\title{
Tidal Variation in Sediment Densities of Marine Benthic Copepods*
}

\author{
Margaret A. Palmer and Rebecca R. Brandt \\ Belle W. Baruch Institute for Marine Biology and Coastal Research, University of South Carolina, Columbia, South Carolina \\ 29208, USA
}

\begin{abstract}
Recent studies have shown that meiofauna frequently occur in the water column and may be highly mobile due to suspension by water currents or any process that disturbs the sediments. We hypothesized that tidal variability in meiofauna sediment densities and distributions may be significant. As a test of this hypothesis, replicate sediment cores were collected in intertidal, slope (creekbank just below water level), and subtidal muds to determine if densities of benthic copepods varied over a tidal cycle. As determined by analysis of variance, the number of copepods within each area clearly varied with the stage of the tide. In the intertidal and subtidal areas there were significantly more copepods in the sediment at both slack high and low tide than at flooding or ebbing tides. This pattern may be due to resuspension of meiofaunal copepods from the sediment into the water column via tidal current action. At the slope site such a tidal response was more complex and observations on the distribution of certain species in the 3 areas suggest that movement of animals occurred between intertidal and slope areas. All intertidal species did not display the same tidal response, and in the slope and subtidal areas all developmental stages (adults, copepodites, nauplii) did not display the same tidal response. These differences were likely due to differences in the size and/or behavior of adults vs juveniles. The processes which likely act to redistribute mud-meiofauna in many systems have hitherto been largely ignored, yet may have important consequences for the communities.
\end{abstract}

\section{INTRODUCTION}

As the tide floods and ebbs over a marine soft-bottom system, there are numerous environmental changes such as alterations in sediment hardness (Perkins, 1958) and turbidity (Einstein and Krone, 1962). Despite these changes, the tidal cycle has rarely been taken into consideration in benthic studies, and sampling has traditionally been done only at low tide (Dye, 1978). Those studies which have examined tidally-controlled phenomena of marine infauna have dealt primarily with vertical movements within the sediment (e.g. Vader, 1964; Johnson, 1967; McLachlan et al., 1977; Dye, 1978). Some notable exceptions have related distribution pattems to sediment reworking (Dillery and Knapp, 1970; Daly and Mathieson, 1977; McLachlan et al., 1979) or to washout and/or tidal migration from high energy sands (e.g. Jones and Naylor, 1970; Alheit and Naylor, 1976).

Certain macroinfauna (e.g. clams) may have limited mobility/dispersal capacity as adults, and their size or mode of living makes it unlikely that they undergo

\footnotetext{
- Contribution No. 370 from the Belle W. Baruch Institute for Marine Biology and Coastal Research
}

horizontal changes over a tidal cycle. However, other macroinfauna (e.g. amphipods), epifauna, and meiofauna are subject to movement by tidal currents and may react to tidal phenomena (Perkins, 1958; Vader, 1964; Boaden, 1968; McLachlan et al., 1977; Grant, 1980). Recent studies have indicated that meiofauna can no longer be considered bound to the sediments but may frequently occur in the water column (Bell and Sherman, 1980; Hagerman, pers. comm.; Sibert, pers. comm.). Thus, the generalizations that emphasize the interstitial nature of meiofauna and their adaptations for life between sediment grains (Swedmark, 1964) cannot be extended to meiobenthos in all systems.

In muddy habitats, where high water content results in a structurally weak and fluid surface (Einstein and Krone, 1962; Thayer, 1975; Young and Southard, 1978), the meiofauna may be highly mobile due to suspension in the overlying water by currents or following any process that disturbs the sediment. We hypothesized that variability in meiofauna sediment densities and distributions may be influenced by such disturbances. As a test of this hypothesis, we synoptically sampled intertidal, slope (creekbank just below water level), and subtidal muds to determine if densities and 
species composition of benthic copepods varied over a tidal cycle. We alleviated the possibility of not sampling copepods that may vertically migrate in the sediment over a tidal cycle by coring to a depth of $3 \mathrm{~cm}-$ considerably deeper than the visible redox potential discontinuity layer. Cores collected in similar areas and fractionated by depth showed that the benthic copepods occurred only in the top $1.5 \mathrm{~cm}$ of sediment (Fleeger, 1980).

Our study was directed at answering four questions:

(1.) Since benthic copepods have traditionally been sampled at low tide and species often categorized as to their occurrence along a tidal gradient (e.g. Coull et al., 1979), many copepods have been considered strictly intertidal or strictly subtidal forms. If samples are collected at various stages of a tidal cycle, is this concept valid or does our past categorization of subtidal and intertidal copepods apply only at low tide?

(2.) Within various study areas (intertidal, slope, subtidal) do sediment densities of benthic copepods vary with the stage of the tide?

(3.) If changes in density occur, do all species within an area display similar changes or is the tidal effect restricted to epibenthic rather than burrowing forms?

(4.) If changes in density occur, do all copepod developmental stages (adults, copepodites, nauplii) display similar changes?

\section{METHODS}

The study area was in the North Inlet Estuary, Georgetown, South Carolina, USA (33 $13^{\prime} \mathrm{N}, 79^{\circ}$ $10^{\prime} \mathrm{W}$ ); a high-salinity, well-mixed estuary (mean tidal range $1.3 \mathrm{~m}$ ) with semidiurnal tides, wide expanses of Spartina alterniflora marsh, and meandering tidal creeks. The intertidal site was an unvegetated mudflat approximately $4.5 \mathrm{~m}$ from a gently sloping $\left(25^{\circ}\right)$ creekbank on which the slope site was located (Fig. 1). Subtidal samples were collected from a creek bottom approximately $3.5 \mathrm{~m}$ from the creekbank. Four replicate samples were taken at each site at slack-low tide,

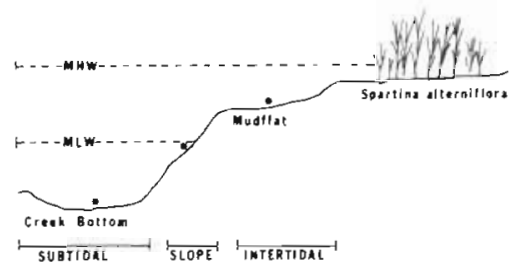

Fig. 1. Diagrammatic view of the 3 sampling areas where sediment cores were collected for determination of benthic copepod densities at different stages of the tide. Mean high water (MHW) and mean low water (MLW) levels are shown. Asterisks ( $(")$ indicate where cores were collected in the subtidal, slope, and intertidal areas mid-flood tide, slack-high tide, and mid-ebb tide on 29 September 1979. Slack-tide samples were collected at cessation of vertical water movement, mid-tide samples exactly $3 \mathrm{~h}$ after the previous high or low tide; water depth was always recorded. Samples were collected with a plastic corer (inner diameter $2.62 \mathrm{~cm}$ ) attached to an adjustable steel rod. Cores were taken at least $0.3 \mathrm{~m}$ apart and preserved in $10 \%$ formalin with rose bengal.

In the laboratory, copepods from each core were extracted by Ludox AM flotation and centrifugation (modified from deJonge and Bouwman, 1977). The supernatant fluid was passed through a $63 \mu \mathrm{m}$ sieve and copepods retained on this sieve sorted, identified, staged, and sexed. Centrifuged pellets were examined to ensure complete enumeration of all copepods. Specific nauplii could not be distinguished and were thus reported as total nauplii.

At the time of sampling, temperature in the water $\left(24{ }^{\circ} \mathrm{C}\right)$ and upper $1 \mathrm{~cm}$ of sediment at each site $\left(24^{\circ} \mathrm{C}\right.$, with a $0.5 \mathrm{C}^{\circ}$ rise intertidally at low tide) was measured with a handheld thermometer. Tidal creek salinity, determined with a refractometer, remained $28 \% \mathrm{~S}$ throughout the 12-h sampling period despite intermittent rain. Three sediment samples were collected at each site at low tide to determine granulometry by wet-sieving and the silt-clay fraction by pipette analysis (Buchanan and Kain, 1971).

\section{RESULTS}

The 3 sampling areas were characterized by soft muddy sediments typical of southeastern salt marshes. Median grain sizes were $26 \mu \mathrm{m}$ intertidally, $12 \mu \mathrm{m}$ in the slope area, and $27 \mu \mathrm{m}$ subtidally. All sites were covered by water during sampling except the intertidal site at low tide (Table 1). Three or 4 copepods were numerically dominant at each site with Microarthridion littorale Poppe and Enhydrosoma propinquum (Brady) common to all 3 areas (Table 2). Dominance did not vary over the tidal cycle, except in the slope area where Halicyclops coulli (Herbst) was extremely

Table 1. Water cover $(\mathrm{cm})$ in intertidal, slope, and subtidal areas at each stage of the tide. Time of sampling in parentheses

\begin{tabular}{|c|c|c|c|c|}
\hline & \multicolumn{4}{|c|}{ Water cover $(\mathrm{cm})$} \\
\hline & $\begin{array}{c}\text { Slack low } \\
(0810)\end{array}$ & $\begin{array}{l}\text { Mid-flood } \\
\quad(1110)\end{array}$ & $\begin{array}{c}\text { Slack high } \\
(1450)\end{array}$ & $\begin{array}{c}\text { Mid-ebb } \\
(1750)\end{array}$ \\
\hline Site & & & & \\
\hline Intertidal & 0 & 12.7 & 86.4 & 45.7 \\
\hline Slope & 5.1 & 71.1 & 124.5 & 96.5 \\
\hline Subtidal & 30.5 & 101.6 & 141.0 & 127.0 \\
\hline
\end{tabular}


Table 2. Number of copepods $10 \mathrm{~cm}^{-2}$ (geometric mean of detransformed data) at low, flood, high, and ebb tides in the intertidal, slope, and subtidal areas. Numbers are based on four replicate samples; $95 \%$ confidence limits in parentheses

\begin{tabular}{|c|c|c|c|c|c|c|c|c|}
\hline & \multicolumn{8}{|c|}{ Abundance } \\
\hline & \multicolumn{2}{|r|}{ Low } & \multicolumn{2}{|r|}{ Flood } & \multicolumn{2}{|r|}{ High } & \multicolumn{2}{|r|}{ Ebb } \\
\hline & $\mathrm{x}$ & C.L. & $x$ & C.L. & $x$ & C.L. & $x$ & C.L. \\
\hline \multicolumn{9}{|l|}{ Intertidal } \\
\hline Microarthridion littorale & 2.70 & $(1.86, \quad 3.92)$ & 0 & $(0)$ & 4.37 & $(1.89,10.09)$ & 2.26 & $(1.64,3.12)$ \\
\hline Enhydrosoma propinquum & 5.46 & $(1.86,28.06)$ & 0.77 & $(0.41,1.45)$ & 1.05 & $(0.44,2.49)$ & 0.59 & $(0.25, \quad 1.41)$ \\
\hline Stenhelia (D.) bifidia & 68.79 & $(42.73,110.75)$ & 19.35 & $(9.26,40.44)$ & 49.34 & $(21.36,113.98)$ & 28.04 & $(15.07,52.15)$ \\
\hline Nannopus palustris & 7.77 & $(2.34,25.80)$ & 10.19 & $(4.92,20.09)$ & 8.80 & $(3.96,19.54)$ & 4.30 & $(2.29,8.08)$ \\
\hline Nauplii & 29.58 & $(2.47,354.07)$ & 5.17 & $(0.81,33.04)$ & 75.10 & $(44.44,126.92)$ & 6.56 & $(1.14,37.85)$ \\
\hline Others & 7.11 & $(4.23,11.94)$ & 7.71 & $(5.35,11.10)$ & 19.10 & $(7.93,46.03)$ & 7.62 & $(3.74,15.54)$ \\
\hline Total & 153.95 & $(85.51,277.11)$ & 46.67 & $(22.60,96.60)$ & 139.44 & $(94.22,206.37)$ & 54.37 & $(33.56,88.08)$ \\
\hline \multicolumn{9}{|l|}{ Slope } \\
\hline Microarthridion littorale & 31.38 & $(25.10, \quad 39.22)$ & 15.70 & $(7.69,32.02)$ & 10.86 & $(4.11,28.67)$ & 21.51 & $(12.08,38.29)$ \\
\hline Enhydrosoma propinquum & 33.06 & $(20.28,53.89)$ & 10.25 & $(3.45,30.04)$ & 7.98 & $(4.78,13.33)$ & 10.49 & $(1.18,93.46)$ \\
\hline Halicyclops coulli & 66.42 & $(10.87,36.49)$ & 5.46 & $(2.55,11.68)$ & 7.25 & $(4.99,10.48)$ & 10.93 & $(2.66,44.92)$ \\
\hline Nauplii & 85.66 & $(72.59,101.07)$ & 15.39 & $(10.26,23.09)$ & 7.41 & $(2.30,23.86)$ & 41.02 & $(28.69,58.66)$ \\
\hline Others & 1.80 & $(0.49, \quad 6.52)$ & 1.80 & $(0.50,6.52)$ & 3.04 & $(1.78, \quad 5.20)$ & 8.49 & $(4.04,17.82)$ \\
\hline Total & 222.91 & $(165.12,300.92)$ & 51.40 & $(27.93,94.58)$ & 39.65 & $(25.4 i, 61.85)$ & 104.42 & $(66.94,162.89)$ \\
\hline \multicolumn{9}{|l|}{ Subtidal } \\
\hline Microarthridion littorale & 7.10 & $(4.23,11.93)$ & 1.27 & $(0.44,3.66)$ & 16.78 & $(6.38,44.13)$ & 5.27 & $(3.13,8.85)$ \\
\hline Enhydrosoma propinquum & 5.27 & $(3.14,8.85)$ & 1.60 & $(0.76,3.31)$ & 3.96 & $(0.99, \quad 15.76)$ & 2,70 & $(0.87,8.91)$ \\
\hline Halicyclops coulli & 23.52 & $(18.67,29.64)$ & 8.22 & $(4.24,15.95)$ & 19.06 & $(12.88,28.20)$ & 11.99 & $(7.14,20.14)$ \\
\hline Nauplii & 33.63 & $(23.03,49.10)$ & 12.30 & $(8.72,17.34)$ & 32.90 & $(21.64,50.00)$ & 4.65 & $(0.99,21.76)$ \\
\hline Others & 4.37 & $(1.89,10.09)$ & 1.80 & $(0.50,6.52)$ & 2.82 & $(1.07, \quad 7.41)$ & 0.35 & $(0.21, \quad 0.61)$ \\
\hline Total & 75.26 & $(56.59,100.09)$ & 27.82 & $(19.45,39.78)$ & 82.06 & $\{54.71,123.09\}$ & 28.67 & $(19.77,41.57)$ \\
\hline
\end{tabular}

abundant at low tide only. Rare species grouped as others in Table 2 included Pseudostenhelia wellsi (Coull and Fleeger), intertidally; Pseudobradya pulchella Sars, Robertsonia propinqua (T. Scott), and Nannopus palustris Brady, in the slope area; Scottolana canadensis (Willey) and Halectinosoma winonae Coull, subtidally; and a few unidentified calanoids and cyclopoids in each area.

Two species encountered in this study, Stenhelia (Delavalia) bifidia Coull and Nannopus palustris were

Table 3. Three-way ANOVA results for the effect of tide (low, flood, high, ebb), area (intertidal, slope, subtidal) and species (Microarthridion littorale, Enhydrosoma propinquum) on the density of copepods $(\log 10[\mathrm{X}+1]$ transformed)

\begin{tabular}{|c|c|c|c|}
\hline Source of variation & $\mathrm{DF}$ & $\begin{array}{l}\text { Sum of } \\
\text { squares }\end{array}$ & F-ratio \\
\hline Tide & 3 & 1.89 & $9.85^{\circ}$ \\
\hline Area & 2 & 7.72 & $60.45^{\cdots}$ \\
\hline Species & 1 & 0.37 & $5.74^{\circ}$ \\
\hline Tide $\times$ area & 6 & 1.02 & $2.65^{\circ}$ \\
\hline Tide $\times$ species & 3 & 0.57 & $2.96^{\circ}$ \\
\hline Area $\times$ species & 2 & 0.08 & $0.61 \mathrm{NS}$ \\
\hline Tide $\times$ area $\times$ species & 6 & 0.28 & $0.73 \mathrm{NS}$ \\
\hline Error & 72 & 4.60 & \\
\hline Total & 95 & 16.52 & \\
\hline \multicolumn{4}{|c|}{$\begin{array}{l}\cdot=\text { significant, } \mathrm{P}<0.05 ; \cdots=\text { significant, } \mathrm{P}<0.001 \\
\mathrm{NS}=\text { not significant }\end{array}$} \\
\hline
\end{tabular}

labeled intertidal species based on previous studies (Coull et al., 1979; Coull, unpubl.). We found these copepods abundant intertidally throughout the tidal cycle and never found them subtidally. However, two adult $N$. palustris occurred in the slope area, one at low tide and one at ebb tide. At the subtidal site we also encountered two species, Scottolana canadensis and Halectinosoma winonae that have typically been labeled subtidal copepods. These animals were never found in the intertidal nor slope area suggesting their categorization as subtidal species appropriate.

The total number of copepods within each area clearly varied with the stage of the tide (Table 2). All data were $\log 10(x+1)$ transformed to meet the homoscedasticity requirement of analysis of variance. A three-way ANOVA was performed to determine the effect of tide, area, and species on the density of copepods in the sediment. Only the 2 species common to all 3 areas, Microarthridion littorale and Enhyrosoma propinquum, were included in the analysis. There was a significant tide effect $(P=0.001)$, indicating that the number of copepods differed between low, flood, high, and ebb tides; a significant species effect $(\mathrm{P}=0.05)$, indicating that the densities of $E$. propinquum and $M$. littorale differed within areas; and a significant area effect $(\mathrm{P}=0.001)$, indicating that different densities of copepods existed between areas (Table 3). 
Tabie 4. Two-way ANOVA results for the effect of tide (low, flood, high, ebb) and species on the density of copepods (log 10 $[\mathrm{X}+1]$ transformed) at the intertidal area, the slope area, and the subtidal area

\begin{tabular}{|c|c|c|c|c|c|c|c|c|c|}
\hline \multirow[b]{2}{*}{ Source of variation } & \multicolumn{3}{|c|}{ Intertidal } & \multicolumn{3}{|c|}{ Slope } & \multicolumn{3}{|c|}{ Subtidal } \\
\hline & DF & $\begin{array}{l}\text { Sum of } \\
\text { squares }\end{array}$ & F-ratio & DF & $\begin{array}{l}\text { Sum of } \\
\text { squares }\end{array}$ & F-ratio & DF & $\begin{array}{l}\text { Sum of } \\
\text { squares }\end{array}$ & F-ratio \\
\hline Tide & 3 & 1.07 & $7.39 \cdot \cdot$ & 3 & 2.83 & $13.33^{*}$ & 3 & 1.44 & $10.11 \cdots$ \\
\hline Species & 3 & 11.43 & $78.85^{\cdots}$ & 2 & 0.17 & $1.19 \mathrm{NS}$ & 2 & 2.16 & $22.77 \cdots$ \\
\hline Tide $\times$ species & 9 & 0.98 & $2.25^{\circ}$ & 6 & 0.61 & $1.43 \mathrm{NS}$ & 6 & 0.39 & $1.38 \mathrm{NS}$ \\
\hline Error & 48 & 2.32 & & 36 & 2.55 & & 36 & 1.71 & \\
\hline Total & 63 & 15.80 & & 47 & 6.16 & & 47 & 5.70 & \\
\hline
\end{tabular}

In order to determine if all species (i.e. not just Microarthridion littorale and Enhydrosoma propinquum) displayed this tidal variation in abundance, two-way ANOVAs for the effect of tide and species on abundances were performed on data for each area. In all 3 areas there was a significant tide effect $(P=0.001)$ on the number of copepods (Table 4). To evaluate the tide effect, multiple comparisons (Tukey's Studentized Range Test) were performed. At the intertidal and subtidal sites, there were significantly more copepods in the sediment at both high and low tide than at flood and ebb tide $(P=0.05)$. At the slope site the pattern was more complex: densities at low tide were significantly greater than at ebb tide, both of which were significantly greater than densities at flood and high tide $(P=0.05)$. A significant species effect $(P=0.001)$ was found intertidally and subtidally; with a significant tide by species interaction intertidally. These results indicate that there was a difference in the densities of the various species within the intertidal and slope areas and that at least intertidally the tidal variation in abundances was different from species to species.

The effect of copepod developmental stage (adult males, females, gravid females, copepodites, nauplii) was determined by a two-way ANOVA of tide and stage on the number of copepods in each area (Table 5). A species effect was not included in this model as nauplii were not distinguishable. We found a significant stage effect in all three areas $(\mathrm{P}=0.001)$ indicating that there were different densities of the various stages. In the slope and subtidal areas significant tide $X$ stage interactions were found reflecting a tidal variation in the proportion of a developmental stage (e. $\mathrm{g}$. nauplii relative to adults) found in the sediment.

\section{DISCUSSION}

The density of benthic copepods in all areas varied significantly during the course of the tidal cycle. At the intertidal and subtidal sites copepod sediment densities were higher at slack low and high tide than at ebbing or flooding tides (Table 2). Since we sampled well below the depth benthic copepods are encountered, the reduced sediment densities reflect the presence of the copepods in the water column. Meiofauna have been collected in water samples (Hauspie and Polk, 1973; Gerlach, 1977; Sibert, pers. comm.) and have, in fact, been found to occur just above the sediment/water interface on a mudflat in our marsh system (Bell and Sherman, 1980). The occurrence of meiofauna in the water column is due to either active migration of the animals from the sediment or passive removal due to current scouring the sediment. Some

Table 5. Two-way ANOVA results for the effect of tide (low, flood, high, ebb) and copepod stage (adult female, adult male, gravid female, copepodite, nauplius) on the density of copepods $(\log 10[\mathrm{X}+1]$ transformed) at the intertidal area, slope area, and subtidal area

\begin{tabular}{|c|c|c|c|c|c|c|c|c|c|}
\hline \multirow[b]{2}{*}{ Source of variation } & \multicolumn{3}{|c|}{ Intertidal } & \multicolumn{3}{|c|}{ Slope } & \multicolumn{3}{|c|}{ Subtidal } \\
\hline & DF & $\begin{array}{l}\text { Sum of } \\
\text { squares }\end{array}$ & F-ratio & $\mathrm{DF}$ & $\begin{array}{l}\text { Sum of } \\
\text { squares }\end{array}$ & F-ratio & DF & $\begin{array}{l}\text { Sum of } \\
\text { squares }\end{array}$ & F-ratio \\
\hline Tide & 3 & 4.11 & $15.32 \cdots$ & 3 & 4.25 & $28.96^{\cdots}$ & 3 & 2.81 & $20.57 \cdots$ \\
\hline Stage & 4 & 3.89 & $10.88^{\cdots}$ & 4 & 3.61 & $18.46^{\circ}$ & 4 & 3.20 & $17.55^{\circ}$ \\
\hline Tide $\times$ stage & 12 & 1.45 & $1.35 \mathrm{NS}$ & 12 & 1.45 & $2.47^{\circ}$ & 12 & 1.06 & $1.93^{\circ}$ \\
\hline Error & 60 & 5.37 & & 60 & 2.94 & & 60 & 2.73 & \\
\hline Total & 79 & 14.83 & & 79 & 12.25 & & 79 & 9.80 & \\
\hline
\end{tabular}


(A) INTERTIDAL

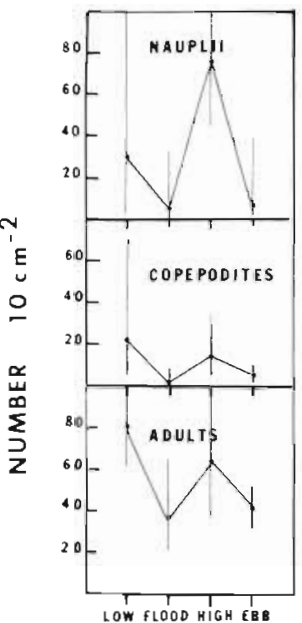

(B) SLOPE

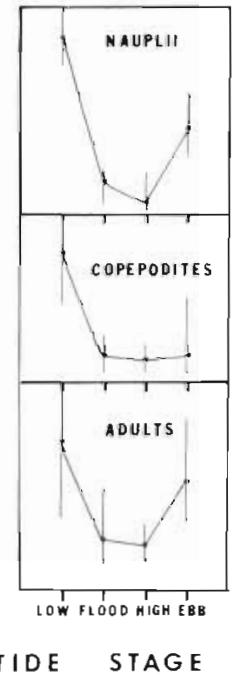

(C) SUBTIDAL

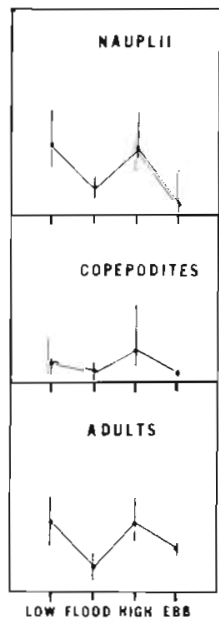

Fig. 2. Abundance $10 \mathrm{~cm}^{-2}$ of naupliar, copepodite, and adult copepods (adult males, females, and gravid females displayed similar responses and were lumped as adults for clarity) at low, flood, high, and ebb tides in the intertidal slope, and subtidal areas. Numbers are geometric means (from detransformed data) based on 4 replicates. See Table 2 for $95 \%$ confidence limits

benthic peracarids are known to emerge actively from sand and display swimming rhythms of tidal frequency (Fincham, 1970; Jones and Naylor, 1970; Alheit and Naylor, 1976). Similar behavior patterns have not been observed in meiobenthos; however, very little is known about their behavior in general. Because of the small size (e.g. Stenhelia (D.) bifidia $\approx 400 \mu \mathrm{m}$ ) and limited swimming abilities of some species, it seems doubtful that meiofauna could maintain their positions in currents that range to $20 \mathrm{~cm} \cdot \mathrm{s}^{-1}$ over the present study area (Palmer, unpubl.). For this reason, we believe the pattern observed in this study was due to resuspension of meiofauna from the sediment into the water column when tidal currents were present (at ebb and flood tides), such that copepod densities were reduced relative to slack tide. Care was taken to ensure that low and high tide samples were collected exactly at slack tide, when water currents and thus resuspension were minimal. This phenomenon of tidal scour and resuspension is not limited to the meiofauna but has been reported to control the spatial distribution of benthic microalgae (Baillie and Welsh, 1980), and has been implicated as an important controlling factor for sand-dwelling haustoriid amphipods (Grant, 1980).

The pattern of highest copepod abundances in the sediment during slack tides did not occur in the slope area; here densities decreased drastically after low tide and did not increase again until ebb tide (Table 2, Fig. 2). The slope data were discrepant with our model based on several other observations. Copepods from other areas (intertidal) were found in the slope area during certain stages of the tide. This suggests that movement of animals, perhaps via sediment runoff with or after ebbing tides, occurred between the slope and intertidal area. The slope area may represent a marginal habitat for some species and the inclination of the slope sediment surface could contribute to increased movement of sediment and/or animals when tidal currents prevail. The dominant slope species occurred across the entire tidal gradient, rendering it impossible to assess further movement of slope copepods to intertidal or subtidal areas.

We have not evaluated actual resuspension and resettlement processes in this study. It is unknown whether settlement is an active swimming/burrowing response or a passive resettlement response. Other studies point to the complexity of such processes and indicate the mode of life (e.g. swimming capabilities) of the species is an important factor (Hauspie and Polk, 1973; Spaargaren, 1979). This may explain the significant tide $x$ species interaction found intertidally (Table 4). Nannopus palustris did not vary in abundance over the tidal cycle as the other dominants (Table $2)$, perhaps because of its large size $(\approx 3$ times larger than Stenhelia (D.) bifidia or Enhydrosoma propinquum) or typically burrowing existence. Furthermore, the significant developmental stage $\times$ tide interactions found at the slope and subtidal areas were likely due to differences in the size and/or behavior of aduits vs juveniles. In our study the nauplii displayed a more dramatic tidal response than adults or copepodites. From one tidal stage to the next subtidal nauplii densities fluctuated 60-70\%, whereas adults fluctuated only about $50 \%$. This agrees with Bell and Sherman (1980) who found large numbers of harpacticoid nauplii in the water column and of Sibert (pers. comm.) whose harpacticoid 'hyperbenthos' was dominated by immature forms. These results suggest that behavior does play a role in the observed tidal patterns. Until more is known about meiofauna behavior, we cannot determine whether it merely modifies a basic resuspension effect (e.g. by determining an animal's susceptibility to resuspension) or is actually responsible for the tidal pattern.

The purpose of our study was to determine if tidal variations in copepod densities within a given area do occur. We have established that such a variation did occur over a short time period (1 tidal cycle) in 3 different areas. The next step of course, is to determine how widespread this phenomenon is over longer time periods, and to investigate possible diurnal or seasonal patterns. The present study indicates that the spatial patterns of meiobenthic copepod communities may be somewhat ephemeral in such systems. Thus, generalizations concerning meiobenthic community structure 
and spatial patterns based only on low tide sampling in a tide-dominated system are likely confounded. This raises questions about sampling methodology in generating reliable estimates of benthic copepod densities. The magnitude of variation we observed for copepod densities from one tide stage to the next was comparable to the seasonal variation in copepod densities that other workers have found. We suggest that when estimating meiobenthic densities, investigators need to consider possible tidal effects in their sampling.

Acknowledgements. We wish to thank B. C. Coull, R. J. Feller, J. Grant, and P. A. Montagna for discussion and critical review of the manuscript. Financial support was provided by the Belle W. Baruch Institute for Marine Biology and Coastal Research, University of South Carolina; by the biological oceanography section, National Science Foundation, Grant \#OCE 8007968 (B. C. Coull, principal investigator); and by a Predoctoral Dissertation Grant to M.A.P. from the Slocum Lunz Foundation.

\section{LITERATURE CITED}

Alheit, J., Naylor, E. (1976). Behavioral basis of intertidal zonation in Eurydice pulchra Leach. J. exp. mar. Biol. Ecol. 23: 135-144

Baillie, P. W., Welsh, B. L. (1980). The effect of tidal resuspension on the distribution of intertidal epipelic algae in an estuary. Estuar. \& coast. mar. Sci. 10: 165-180

Bell, S. S., Sherman, K. S. (1980). Tidal resuspension as a mechanism for meiofauna dispersal. Mar. Ecol. Prog. Ser. 3: $245-249$

Boaden, P. J. S. (1968). Water movement - a dominant factor in interstitial ecology. Sarsia 34: 125-136

Buchanan, J. B., Kain, J. M. (1971). Measurement of the physical and chemical environment. In: Holme, N. A., McIntyre, A. D. (eds) Methods for the study of marine benthos. Blackwell Scientific Publications, Oxford, pp. $30-51$

Coull, B. C., Bell, S. S., Savory, A. M. Dudley, B. W. (1979). Zonation of meiobenthic copepods in a southeastern United States salt marsh. Estuar. \& coast. mar. Sci. 9: $181-188$

Daly, M. A., Mathieson, A. C. (1977). The effects of sand movement on intertidal seaweeds and selected inverte- brates at Bound Rock, New Hampshire, USA. Mar. Biol. 43: $45-55$

deJonge, V N., Bouwman, L. A. (1977). A simple density separation technique for quantitative isolation of meiobenthos using the colloidal silica Ludox-TM. Mar. Biol. 42: 143-148

Dillery, D. G., Knapp, L. V. (1970). Longshore movements of the sand crab, Emerita analoga (Decapoda, Hippidae). Crustaceana 18: 233-240

Dye, A. H. (1978). Diumal vertical migrations of meiofauna in an estuarine sand flat. Zool. Afr. 13: 201-205

Einstein, H. A., Krone, R. B. (1962). Experiments to determine modes of cohesive sediment transport in salt water. J. geophys. Res. 67 : 1451-1461

Fincham, A. A. (1970). Amphipods in the surf plankton. J. mar. biol. Ass. U.K. 50: 177-198

Fleeger, J. W. (1980). Community structure of an estuarine meiobenthic copepod assemblage. Estuar. \& coast. mar. Sci. 10: $107-117$

Gerlach, S. A. (1977). Means of meiofauna dispersal. Mikrofauna Meeresboden 61: 89-103

Grant, J. (1980). A flume study of drift in marine infaunal amphipods (Haustoriidae). Mar. Biol. 56: 79-84

Hauspie, R., Polk, P. H. (1973). Swimming behavior patterns in certain benthic harpacticoids (Copepoda). Crustaceana 25: $95-103$

Johnson, R. G. (1967). The vertical distribution of the infauna of a sand flat. Ecology 48: 571-578

Jones, D. A., Naylor, E. (1970). The swimming rhythm of the sand beach isopod Eurydice pulcra. J. exp. mar. Biol. Ecol. 4: $188-199$

McLachlan, A., Erasmus, T., Furstenberg, J. P. (1977). Migrations of sandy beach meiofauna. Zool. Afr. 12: 257-277

McLachlan, A., Wooldridge, T., van der Horst, G. (1979). Tidal movements of the macrofauna on an exposed sandy beach in South Africa. J. Zool., Lond. 188: 433-442

Perkins, E. J. (1958). The hardness of the soil of the shore at Whitstable, Kent. J. Ecol. 46: 71-81

Spaargaren, D. H. (1979). Hydrodynamic properties of benthic marine Crustacea. I. Specific gravity and drag coefficients. Mar. Ecol. Prog. Ser. 1: 351-359

Swedmark, B. (1964). The interstitial fauna of marine sand. Biol. Rev. 39: 1-42

Thayer, C. W. (1975). Morphologic adaptations of benthic invertebrates to soft substrata. J. mar. Res. 33: 177-189

Vader, W. J. M. (1964). A preliminary investigation into the reactions of the infauna of the tidal flats to tidal fluctuations of water level. Neth. J. Sea Res. 2: $189-222$

Young, R. N., Southard, J. B. (1978). Erosion of fine-grained marine sediments. Sea-floor and laboratory experiments. Geol. Soc. Am. Bull. 89: 683-672 